\title{
UV-Excited Fluorescence on Riparian Insects except Hymenoptera Is Associated with Nitrogen Content
}

\author{
William D. Wiesenborn \\ USDI Bureau of Reclamation, Lower Colorado Regional Office, P.O. Box 61470, \\ Boulder City, NV 89006, USA \\ Correspondence should be addressed to William D. Wiesenborn,wwiesenborn@usbr.gov
}

Received 13 January 2011; Revised 30 March 2011; Accepted 30 March 2011

Academic Editor: Ai-Ping Liang

Copyright (๑) 2011 William D. Wiesenborn. This is an open access article distributed under the Creative Commons Attribution License, which permits unrestricted use, distribution, and reproduction in any medium, provided the original work is properly cited.

I photographed ultraviolet-excited fluorescence of external resilin on insects in 7 orders, 17 families, and 18 genera collected from shrubs and trees alongside the Colorado River in western Arizona, USA. The localized blue-fluorescence characteristic of resilin was emitted by a variety of structures including sutures and wing articulations on Odonata and Diptera and membranous wings, compound eyes, or ocelli on Hemiptera, Neuroptera, and Hymenoptera. Different widespread, but blotchy, light-blue fluorescence was observed on cuticles of immature Orthoptera and adult Hemiptera. Insects in Hymenoptera and Coleoptera fluoresced least. Ranked amounts of fluorescence, relative to body area, were positively correlated with ranked nitrogen contents (\% $\mathrm{N}$ of body dry-mass) of insects in genera excluding Hymenoptera. Nitrogen concentrations in insect exoskeletons appear to increase as abundances of resilin and other fluorescent, elastic proteins increase. These structural compounds may be an important nitrogen source for insectivorous vertebrates.

\section{Introduction}

Resilin is a structural protein in insects that fluoresces in ultraviolet (UV) light. It provides elasticity to the exoskeleton and was first described, as rubber-like, in the wing hinges and tendons of dragonflies and locusts [1]. The blue fluorescence (maximum at $420 \mathrm{~nm}$ ) of resilin [2] is emitted by dityrosine and trityrosine, two phenolic amino-acids within the protein's chains that cross-link the chains together $[3,4]$. Greatest fluorescence is produced when resilin is placed in alkaline solution [2] and excited with long-wave UV light $(310-340 \mathrm{~nm})$ [3]. The characteristic fluorescence of resilin has been used to detect the protein in a variety of structures on a diversity of insects. Resilin has been found in wing hinges [2] and legs [5] on cockroaches, abdominal springs [2] and wings [6] on beetles, jumping-mechanisms on froghoppers [7] and cicadas [8], wing-vein joints on damselflies [9], tendons [2] and tarsal joints [10] on blow flies, stretchable abdomens on honey ants [11], and venom injectors on honey bees [12]. Resilin may not be the only compound in insects that fluoresces under UV light. Blue fluorescence by the epicuticle of locusts has been noted $[13,14]$, possibly resulting from aromatic compounds [13] such as tyrosine-derived cross-links between epicuticular layers [15].

Resilin may be associated with insect nitrogen $(\mathrm{N})$ content. The protein contains a high $\mathrm{N}$ concentration, estimated at $19 \%$ [16], and can occur in near-pure concentrations or combined with other cuticular proteins and chitin [17]. Chitin is a nitrogenous polysaccharide that contains less $\mathrm{N}(6.9 \%)$ than protein and typically comprises $25-40 \%$ of cuticle dry mass [17]. Resilin is not sclerotized and therefore easily hydrolyzed [17] and digested by animals. Insectivorous vertebrates, such as birds, may utilize resilin as an $\mathrm{N}$ source. $\mathrm{N}$ mass in a variety of spiders and insects collected in riparian habitat was related allometrically to body dry-mass, suggesting that most $\mathrm{N}$ resides within the exoskeleton, and dependent on arthropod order but not family [16]. Spiders are not known to contain resilin, and abundances of resilin in insects may vary among orders [2]. My objective here is to examine external UV-excited fluorescence on riparian 
insects in different families and orders and test if amounts of fluorescence are associated with body $\% \mathrm{~N}$ contents.

\section{Methods}

2.1. Collecting Insects. I collected insects during the period from 3 May to 15 September 2010 on the Colorado River floodplain within Havasu National Wildlife Refuge in Mohave County, Arizona, USA. Insects were collected within or near a 43-ha plot of trees and shrubs $\left(34^{\circ} 46^{\prime} \mathrm{N}, 114^{\circ}\right.$ $31^{\prime} \mathrm{W}$; elevation $143 \mathrm{~m}$ ), planted primarily for insectivorous birds, $12 \mathrm{~km}$ southeast and across the river from Needles, California. Two impoundments, Topock Marsh (1600 ha) and Beal Lake (90 ha), straddle the plot. Insects were collected in separate sweepings of Populus fremontii S. Watson, Salix gooddingii C. Ball, and Salix exigua Nutt. (Salicaceae), Pluchea sericea (Nutt.) Cov. (Asteraceae), and naturalized Tamarix ramosissima Ledeb. (Tamaricaceae) and combined sweepings of Prosopis glandulosa Torrey and Prosopis pubescens Benth. (Fabaceae). I also captured flying insects with a Malaise trap. Insects were stored in 70\% ethanol.

2.2. Photographing Fluorescence. I examined UV-excited fluorescence on insects with digital photography. The alkalinity of insects was increased to $\mathrm{pH} 9$ by adding $0.25 \mathrm{~N} \mathrm{NaOH}$ to the $70 \%$ ethanol ( 4 drops $/ 5 \mathrm{~mL}$ ). After being treated overnight, insects were removed from the ethanol and dried with absorbent paper. I illuminated each insect with a longwave UV light-source constructed by replacing the filter on a UV lamp (Mineralight UVS-12, UVP, Upland, Calif., USA) with a filter that only transmits 310-390 nm (Hoya U-360, Edmund Optics no. NT46-442, Barrington, NJ, USA). UV light was projected at a $45^{\circ}$ angle downwards $5 \mathrm{~cm}$ onto the insect and reflected onto the insect's opposite-side with a UVreflective mirror (Edmund Optics no. A45-337). Insects were photographed with a digital camera (Sony DSC-H1), set for around $8 \mathrm{sec}$ exposures, against a black background while illuminated with UV and fluorescent room-lighting. I balanced the blue fluorescence with reflectance of visible light by blocking the room lighting with layers of fine-mesh polyester netting. I photographed the insect's entire lateral view, or its entire dorsal and ventral views if dorsoventrally flattened. Magnification was increased by attaching a reversed $50 \mathrm{~mm}$ lens for a $35 \mathrm{~mm}$ film camera in front of the digital-camera lens. All insects photographed $(n=47,1-8$ specimens per genus) were collected during 2010 except for an adult Tettigoniidae collected at the same locality during 2009 [16] and kept in $70 \%$ ethanol. Color intensity of photographs in Figures 1-5 was increased with Photo-Paint (Corel, Ottawa, Ontario, Canada).

2.3. Identifying Insects. Adult insects were identified at least to genus after being photographed. They were keyed or compared with identified specimens swept from the same plants in 2009 [16]. I assumed nymphal Acrididae to be the same species as an adult Melanoplus herbaceus Bruner swept from the same arrowweed (P. sericea) plants, the grasshopper's primary host [18]. Voucher insects were

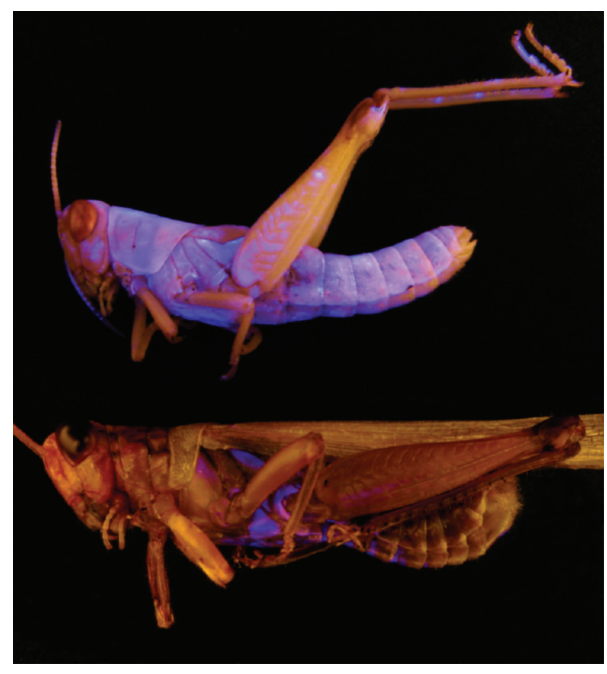

FIGURE 1: Blue fluorescence in UV light on a nymph (top) and adult male (bottom) Melanoplus herbaceus (Orthoptera: Acrididae). Photos not to scale. Color intensity digitally increased.



FIGURE 2: Blue fluorescence in UV light on dorsum (top) and ventrum (bottom) of Brochymena sulcata (Hemiptera: Pentatomidae). Color intensity digitally increased.

deposited at the Entomology Department insect collection, University of Arizona, Tucson.

2.4. Comparing Fluorescence with Nitrogen Content. I compared amounts of fluorescence with estimates of $\% \mathrm{~N}$ in insects collected during 2009 [16, Table 1]. In this previous study, $\mathrm{N}$ mass in spiders, adult insects, and immature Acrididae (swept from $P$. sericea and similar to those in 2010) was measured with Kjeldahl digestion, and \% $\mathrm{N}$ was calculated from body dry-mass. Mean estimates of $\% \mathrm{~N}$ in 




FIGURE 3: Blue fluorescence in UV light on ventrolateral (top) and dorsal (bottom, anterior at left) views of the thorax of the dragonfly Pachydiplax longipennis (Odonata: Libellulidae). Color intensity digitally increased.

insects within the same genera photographed were ranked across genera. Amounts of fluorescence on insects also were ranked across genera. One lateral-view photograph, or a pair of dorsal- and ventral-view photographs, of each genus was printed that showed fluorescence representative of the other specimens within the genus. I arranged prints of genera in ascending order by total area of fluorescence relative to the insect surface-area photographed. Less importance was given to fluorescence on membranous wings, as on Cixiidae and Chrysopidae, due to their thinness and small proportion of body dry-mass. Association between ranked $\% \mathrm{~N}$ and ranked relative-area of fluorescence of insects classified by genus was tested with Spearman's rank correlation [19].

\section{Results}

Blue fluorescence in UV light was greatest on immature Acrididae (Orthoptera). Nymphs of $M$. herbaceus displayed a grainy, light-blue fluorescence abundantly distributed over their entire pronotum, lateral thorax, and abdomen (Figure 1). Blotches of fluorescence also were detected on their gena, femur, tibia, and tarsus. Less fluorescence was observed on an adult male $M$. herbaceus (Figure 1). Deepblue fluorescence was apparent on its metasternum, metepisternum, and part of its mesepisternum, while the bases of its proximal abdominal-sterna also fluoresced. The other orthopteran examined, an adult female tettigoniid (Scudderia furcata Brunner), displayed blotchy blue-fluorescence on its gena and abdomen.

Hemiptera displayed varying amounts of blue fluorescence. Fluorescence was abundant on the pentatomid Brochymena sulcata Van Duzee (Figure 2). All of its abdomi-



Figure 4: Blue fluorescence in UV light on Acinia picturata (Diptera: Tephritidae) (top) and Minettia flaveola (Diptera: Lauxaniidae) (bottom). Color intensity digitally increased.

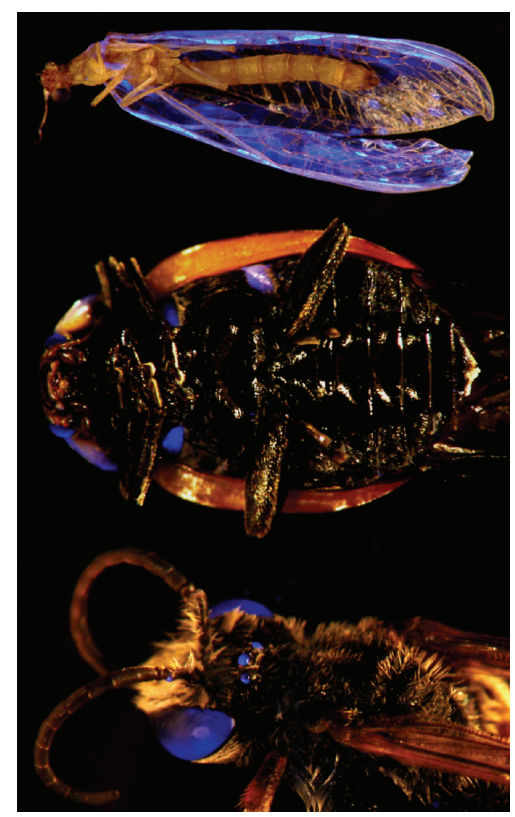

FIGURE 5: Blue fluorescence in UV light on Chrysoperla sp. (Neuroptera: Chrysopidae) (top), Hippodamia convergens (Coleoptera: Coccinellidae) (middle), and Dieunomia nevadensis (Hymenoptera: Halictidae) (bottom). Color intensity digitally increased.

nal sterna produced a mottled, light-blue fluorescence, and the membrane of each front wing similarly fluoresced in irregularly shaped patches that were not distinctive in visible light. Less fluorescence was detected on the specimen of Reduviidae (Zelus sp.). Its ventral thorax and abdomen fluoresced unevenly, whereas on its dorsum the ocelli fluoresced 
strongly and the compound eyes fluoresced weakly. The compound eyes of the Cixiidae (Oecleus sp.) also fluoresced blue, along with the lower margin of the clypeus. Uneven fluorescence was observed on the medial one-third of its forewings.

Various structures on Odonata fluoresced blue. Most fluorescence on the dragonfly Pachydiplax longipennis Burmeister (Libellulidae) (Figure 3) was produced by translucentwhite cuticle attached to the axillary and humeral plates [20] below the base of each front and hind wing. The articulations above the wings similarly fluoresced blue. Broad bands of whitish cuticle ventrally joining the thorax and abdomen also fluoresced. Narrow bands of fluorescence were detected between the front coxa and trochanter, at the bases of the middle and hind coxae, and at the margins of the abdominal sterna.

Diptera exhibited intermediate amounts of blue fluorescence. Fluorescence was most evident on the tephritid Acinia picturata (Snow) (Figure 4). Its haltere was the most distinctive structure that fluoresced, and fluorescence was also observed at the articulation below the wing, along the notopleural and pleural sutures [21], and on sterna at the base of the abdomen. Fluorescence on Tachinidae (Zaira sp.) was similarly detected at the articulation below the wing and along the notopleural and pleural sutures but also at the base of the front coxa. The lauxaniid Minettia flaveola Coquillett (Figure 4) fluoresced blue at its wing articulation, along the notopleural suture, and at the sutures at the base of the front and middle coxae. The Tabanidae (Tabanus sp.) showed weak fluorescence at the base of its wings in dorsal view and on the prosternal, precoxal bridge [21] in ventral view.

Green lacewings (Chrysoperla sp. [Neuroptera: Chrysopidae]) fluoresced across approximately $25 \%$ of their wings (Figure 5). Fluorescence differed between the two genera of Coleoptera examined, both in Coccinellidae. Hippodamia convergens Guerin-Meneville fluoresced strongly on the mesepimeron and metepimeron (Figure 5), both lightbrown in visible light and in contrast with the dark-brown ventrum. Weak fluorescence was seen dorsally and ventrally on its compound eyes and on the lateral margins of its pronotum. Fluorescence was absent on the lower and upper surfaces, including the hind wings, of Chilocorus cact $i \mathrm{~L}$.

Fluorescence was absent or nearly absent on Hymenoptera. The compound eyes and ocelli fluoresced blue on bees in Halictidae (Dieunomia nevadensis [Cresson]) (Figure 5), and a bee in Andrenidae (Perdita sp.) fluoresced along a short, faint line behind the pronotum and below the pronotal lobe. Fluorescence was not detected on the Formicidae (Formica sp.), Tiphiidae (Myzinum frontalis [Cresson]), or Vespidae (Polistes sp.) photographed.

Insect genera tended to cluster by order when ranked $\% \mathrm{~N}$ was plotted against ranked relative-area of fluorescence (Figure 6). For example, genera in Hymenoptera exhibited high $\mathrm{N}$-content but near-zero fluorescence, whereas genera in Hemiptera exhibited intermediate N-content and abundant fluorescence. Ranked correlation between $\% \mathrm{~N}$ and relative area of fluorescence of insects classified by genus depended on order. Nitrogen content and fluorescence were not correlated $(r=.02 ; n=18 ; t=.06 ; P=.95)$ when

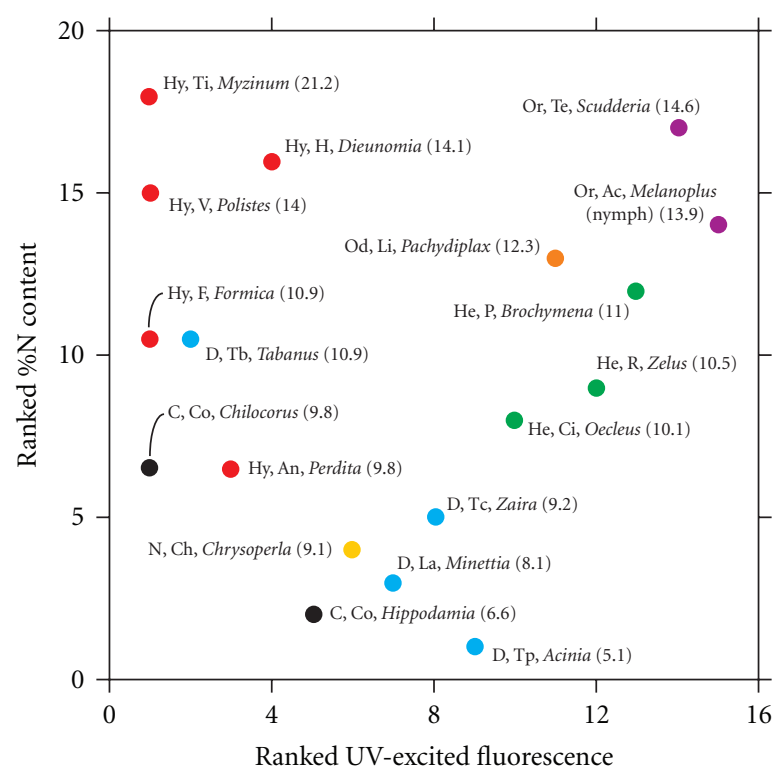

Figure 6: Adult insects ranked and plotted by genera in relation to mean $\% \mathrm{~N}$ of body dry-mass (in parentheses, from [16, Table 1]) and area of UV-excited fluorescence relative to body surface-area. First abbreviations are orders: C: Coleoptera; D: Diptera; He: Hemiptera; Hy: Hymenoptera; N: Neuroptera; Od: Odonata; Or: Orthoptera. Second abbreviations are families: Ac: Acrididae; An: Andrenidae; Ch: Chrysopidae; Ci: Cixiidae; Co: Coccinellidae; F: Formicidae; H: Halictidae; La: Lauxaniidae; Li: Libellulidae; P: Pentatomidae; R: Reduviidae; Tb: Tabanidae; Tc: Tachinidae; Te: Tettigoniidae; Ti: Tiphiidae; Tp: Tephritidae; V: Vespidae.

all orders were considered. A positive correlation $(r=.65$; $n=13 ; t=2.82 ; P=.017)$ was detected when Hymenoptera were excluded. Nitrogen content generally increased as the relative-area of fluorescence increased in genera of Coleoptera, Neuroptera, Diptera, Hemiptera, Odonata, and Orthoptera.

\section{Discussion}

Two types of UV-excited fluorescence were observed on insects. One type was a saturated, blue fluorescence that was localized to specific structures. This was best represented by fluorescence of the translucent-white cuticle above and below each wing on the dragonfly P. longipennis. These structures are the wing-hinge ligaments, comprised of resilin, identified on Aeshna dragonflies [2]. Similar fluorescence of resilin in dorsal wing-ligaments was photographed on the locust Schistocerca gregaria (Forskål) [2, Figure 2]. Localized blue-fluorescence on the insects I examined likely indicates resilin. The second type is the abundant but blotchy, light-blue fluorescence seen on the nymphal grasshopper M. herbaceus, the katydid S. furcata, and the hemipterans Brochymena and Zelus. Neville [14] similarly described a cuticular fluorescence on locusts as blue and as brighter than that of resilin. This type of fluorescence has been attributed to the epicuticle $[13,14]$, the thin, outermost layer of the exoskeleton. A superficial origin of the fluorescence is 
suggested by its blotchiness that was especially apparent on B. sulcata. This fluorescence was not randomly dispersed, however, as it was mostly absent on the legs and heads of $M$. herbaceus nymphs and limited to the abdominal sterna on B. sulcata. In addition, it was observed on immature, but not adult, $M$. herbaceus. The adult $M$. herbaceus exhibited only the localized blue-fluorescence characteristic of resilin, primarily on its metathorax.

Fluorescence from either resilin or the epicuticle was positively associated with $\mathrm{N}$ contents in insects other than Hymenoptera. This agrees with the suggestion that epicuticular fluorescence is emitted by tyrosine-derived protein cross-links [15] similar to those found in resilin. Greater protein concentration in fluorescent epicuticle, as frequently found in cuticle containing resilin [17], may enable elasticity. Expandable abdominal-cuticles on Rhodnius (Hemiptera: Reduviidae) contain unusually low concentrations of chitin (11\%) [22] resulting in high protein and $\mathrm{N}$ concentrations. Abdominal sterna on predatory B. sulcata also may expand. Cuticles on $M$. herbaceus nymphs were more flexible than on adults, suggesting lower chitin and higher protein contents.

Most incongruous was the lack or near-lack of fluorescence on Hymenoptera despite high $\mathrm{N}$ contents. This may have resulted from several factors. First, the indirect flight-muscles of wasps and bees would not require the large, resilin wing-hinges observed on insects with direct flight-muscles such as grasshoppers and dragonflies [2]. Second, the abdominal cuticles on adult ants, wasps, and bees likely do not need to stretch, because these insects typically eat pollen or nectar rather than the large, single meals eaten by adult predators such as reduviids. The stretchable abdomens on honey ants are an exception due to the large quantities of sugar solution they store [11]. Third, the articular membranes [20] between sclerites may be hidden on Hymenoptera. The strongly fluorescing sutures on $M$. flaveola flies, especially at the coxal attachments, were visible in normal light as pale-colored membranes between sclerites. Similar membranes were not visible on Hymenoptera. Instead, the thoracic sclerites appeared to adjoin. Compositions of hymenopteran exoskeletons also may differ from those on other orders.

Photographs of UV-excited fluorescence revealed some unusual structures that appear to contain resilin. One is the halteres on A. picturata. Halteres provide equilibrium to flies by oscillating vertically on a hinge with a frequency determined by contractions of a single muscle and the haltere's mechanical resonance [23]. Resilin within halteres would allow them to bend and rebound at the end of each stroke. The base of each haltere also contains a campaniform sensillum [23], a proprioceptor suspected to contain resilin [24]. Other unusual structures that fluoresced are the ocelli or compound eyes on the Zelus assassin bug, Oecleus planthopper, Hippodamia ladybird beetle, and Dieunomia bee. Resilin in the cuticle covering these structures was first hypothesized in S. gregaria locusts and suggested to be related to transparency [2]. Fluorescent dityrosine and trityrosine were later isolated from compound-eye corneas of the beetle Photinus pyralis L. [25] and S. gregaria [15]. Also unusual was the glimmering fluorescence of the membranous wings on Chrysoperla green lacewings and Oecleus, similar to the patchy fluorescence of the front-wing membranes on Brochymena. Resilin has been detected as small areas of fluorescence on membranous hind-wings of scarab and coccinellid beetles [6]. Elasticity in wings was suggested to assist flight and enable hind wings of beetles to fold under the elytra [6]. I observed fluorescence of membranous wings that do not fold in Hemiptera and Neuroptera. In these orders, elasticity may also facilitate wing expansion by teneral adults. Why the compound eyes, ocelli, and membranous wings of some genera fluoresced while those of others did not remains unclear.

The ranked correlation between fluorescence and \% $\mathrm{N}$ of riparian insects has at least two limitations. One, the low number of taxa examined, especially within orders, may not be representative of other insects. Two, fluorescence was subjectively ranked rather than measured and cannot be used to predict $\mathrm{N}$ content. Measuring external fluorescence relative to insect surface-area would be difficult and unable to account for cuticle thickness. Different patterns of fluorescence among life stages, even in hemimetabolous insects such as $M$. herbaceous, or between sexes also would complicate measurements within species.

Positive association between $\mathrm{N}$ content of riparian insects other than Hymenoptera and UV-excited fluorescence of cuticular proteins including resilin suggests these compounds are important sources of $\mathrm{N}$ for insectivorous vertebrates. Areas of the exoskeleton with elasticity, indicating lack of sclerotization and low chitin contents, would provide high concentrations of digestible N. Variation in concentrations of resilin and similar digestible proteins in exoskeletons, especially among orders, may influence prey selection by insectivorous birds and other wildlife.

\section{Acknowledgments}

The author thanks James O'Hara at Agriculture and AgriFood Canada for identifying the tachinid. He also appreciates the collection permit provided by Jack Allen at Havasu National Wildlife Refuge. This work was funded by the Lower Colorado River Multi-Species Conservation Program.

\section{References}

[1] T. Weis-Fogh, "A rubber-like protein in insect cuticle," Journal of Experimental Biology, vol. 37, no. 4, pp. 889-907, 1960.

[2] S. O. Andersen and T. Weis-Fogh, "Resilin. A rubberlike protein in arthropod cuticle," in Advances in Insect Physiology, J. W. L. Beament, J. E. Treherne, and V. B. Wigglesworth, Eds., vol. 2, pp. 1-65, Academic Press, London, UK, 1964.

[3] S. O. Andersen, "Characterization of a new type of crosslinkage in resilin, a rubber-like protein," Biochimica et Biophysica Acta, vol. 69, pp. 249-262, 1963.

[4] S. O. Andersen, "The cross-links in resilin identified as dityrosine and trityrosine," Biochimica et Biophysica Acta, vol. 93, no. 1, pp. 213-215, 1964.

[5] D. Neff, S. F. Frazier, L. Quimby, R. T. Wang, and S. Zill, "Identification of resilin in the leg of cockroach, Periplaneta americana: confirmation by a simple method using $\mathrm{pH}$ dependence of UV fluorescence," Arthropod Structure and Development, vol. 29, no. 1, pp. 75-83, 2000. 
[6] F. Haas, S. Gorb, and R. Blickhan, "The function of resilin in beetle wings," Proceedings of the Royal Society B, vol. 267, no. 1451, pp. 1375-1381, 2000.

[7] M. Burrows, S. R. Shaw, and G. P. Sutton, "Resilin and chitinous cuticle form a composite structure for energy storage in jumping by froghopper insects," BMC Biology, vol. 6, article no. 41, 2008.

[8] S. N. Gorb, "The jumping mechanism of cicada Cercopis vulnerata (Auchenorrhyncha, Cercopidae): skeleton-muscle organisation, frictional surfaces, and inverse-kinematic model of leg movements," Arthropod Structure and Development, vol. 33, no. 3, pp. 201-220, 2004.

[9] S. N. Gorb, "Serial elastic elements in the damselfly wing: mobile vein joints contain resilin," Naturwissenschaften, vol. 86, no. 11, pp. 552-555, 1999.

[10] S. Niederegger and S. Gorb, "Tarsal movements in flies during leg attachment and detachment on a smooth substrate," Journal of Insect Physiology, vol. 49, no. 6, pp. 611-620, 2003.

[11] A. R. Varman, "Resilin in the abdominal cuticle of workers of the honey-ants, Myrmecocystus mexicanus," Journal of the Georgia Entomological Society, vol. 16, no. 1, pp. 11-13, 1981.

[12] H. R. Hermann and D. E. Willer, "Resilin distribution and its function in the venom apparatus of the honey bee, Apis mellifera L. (Hymenoptera : Apidae)," International Journal of Insect Morphology and Embryology, vol. 15, no. 1-2, pp. 107114, 1986.

[13] T. Weis-Fogh, "Structure and formation of insect cuticle," in Insect Ultrastructure, A. C. Neville, Ed., Symposia of the Royal Entomological Society of London, no. 5, pp. 165-185, Blackwell Scientific, Oxford, UK, 1970.

[14] A. C. Neville, "Biology of the Arthropod Cuticle," in Zoophysiology and Ecology, D. S. Farner, Ed., vol. 4/5, p. 448, Springer, New York, NY, USA, 1975.

[15] S. O. Andersen, "Regional differences in degree of resilin cross-linking in the desert locust, Schistocerca gregaria," Insect Biochemistry and Molecular Biology, vol. 34, no. 5, pp. 459466, 2004.

[16] W. D. Wiesenborn, "Nitrogen content in riparian arthropods is most dependent on allometry and order," Florida Entomologist, vol. 94, no. 1, pp. 71-80, 2011.

[17] A. G. Richards, "The chemistry of insect cuticle," in Biochemistry of Insects, M. Rockstein, Ed., pp. 205-232, Academic Press, New York, NY, USA, 1978.

[18] H. F. Strohecker, W. W. Middlekauff, and D. C. Rentz, The grasshoppers of California (Orthoptera: Acridoidea), vol. 10 of Bulletin of the California Insect Survey, University of California Press, Berkeley, Calif, USA, 1968.

[19] R. G. D. Steel and J. H. Torrie, Principles and Procedures of Statistics: A Biometrical Approach, McGraw-Hill, New York, NY, USA, 2nd edition, 1980.

[20] R. E. Snodgrass, Principles of Insect Morphology, McGraw-Hill, New York, NY, USA, 1935.

[21] F. R. Cole, The Flies of Western North America, University of California Press, Berkeley, Calif, USA, 1969.

[22] R. H. Hackman, "Expanding abdominal cuticle in the bug Rhodnius and the tick Boophilus," Journal of Insect Physiology, vol. 21, no. 9, pp. 1613-1623, 1975.

[23] J. W. S. Pringle, "The gyroscopic mechanism of the halteres of Diptera," Philosophical Transactions of the Royal Society of London, Series B, vol. 233, no. 602, pp. 347-384, 1948.
[24] D. T. Moran, K. M. Chapman, and R. A. Ellis, "The fine structure of cockroach campaniform sensilla," Journal of Cell Biology, vol. 48, no. 1, pp. 155-173, 1971.

[25] A. Sannasi, "Resilin in the lens cuticle of the firefly, Photinus pyralis Linnaeus," Experientia, vol. 26, no. 2, p. 154, 1970. 

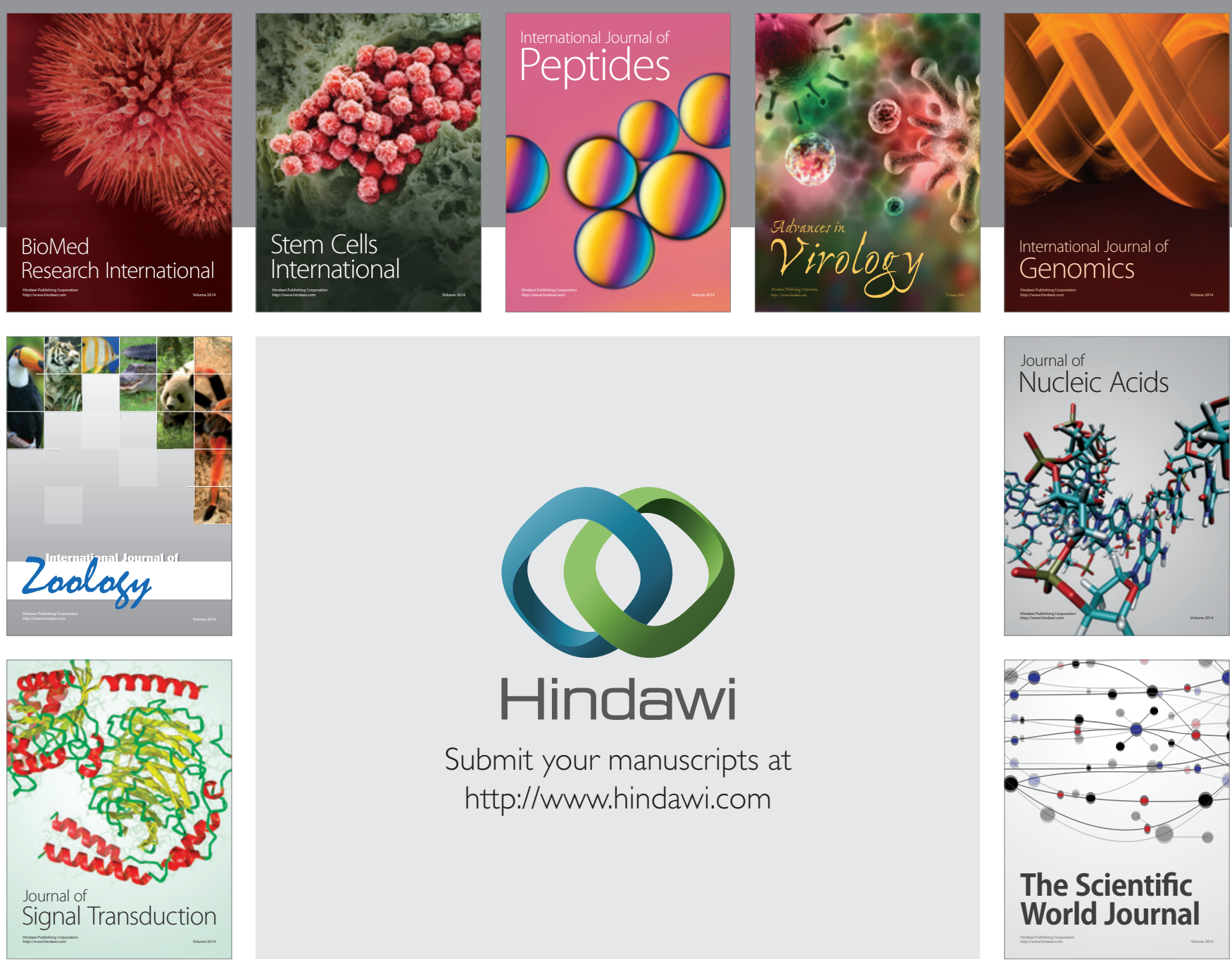

Submit your manuscripts at

http://www.hindawi.com
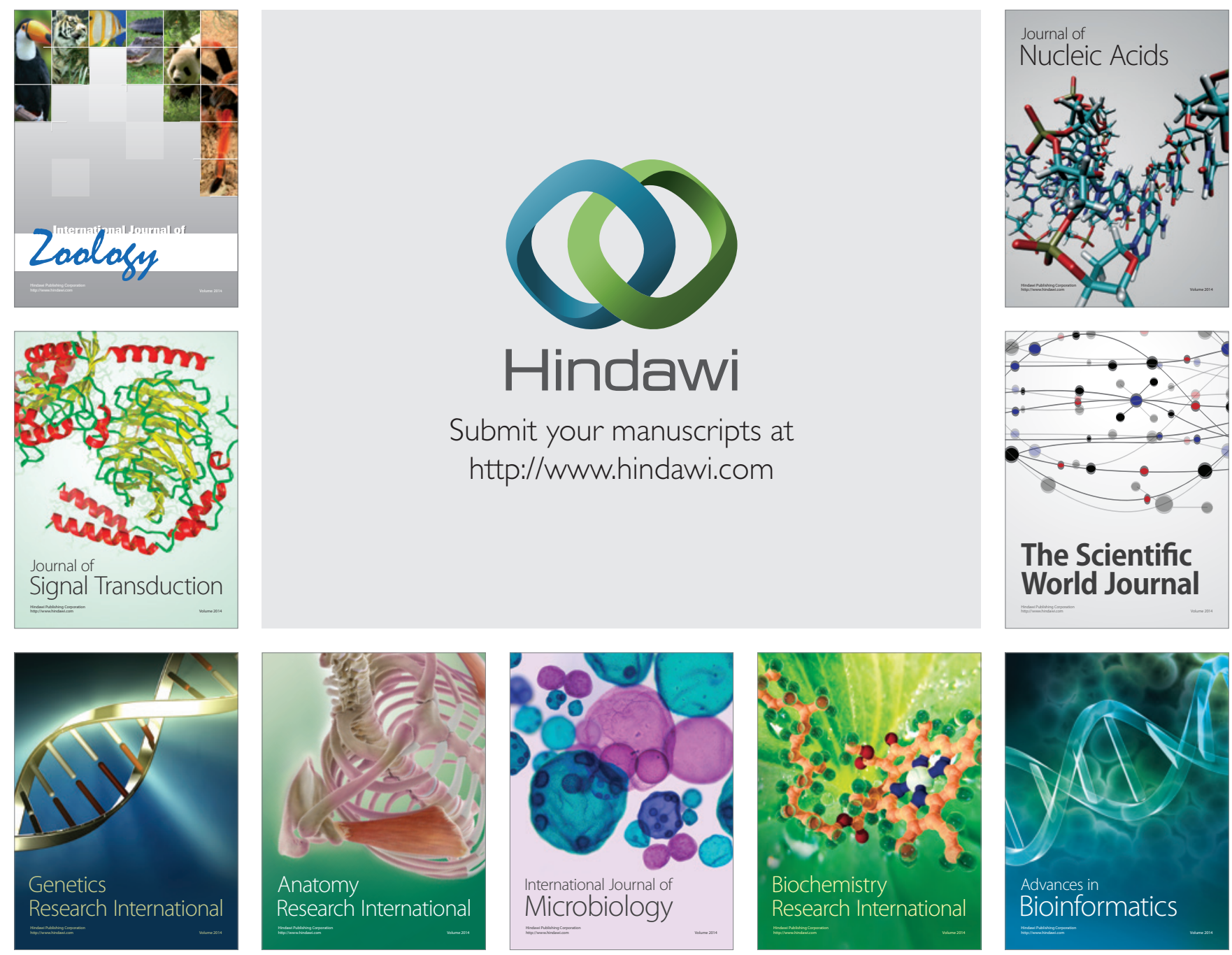

The Scientific World Journal
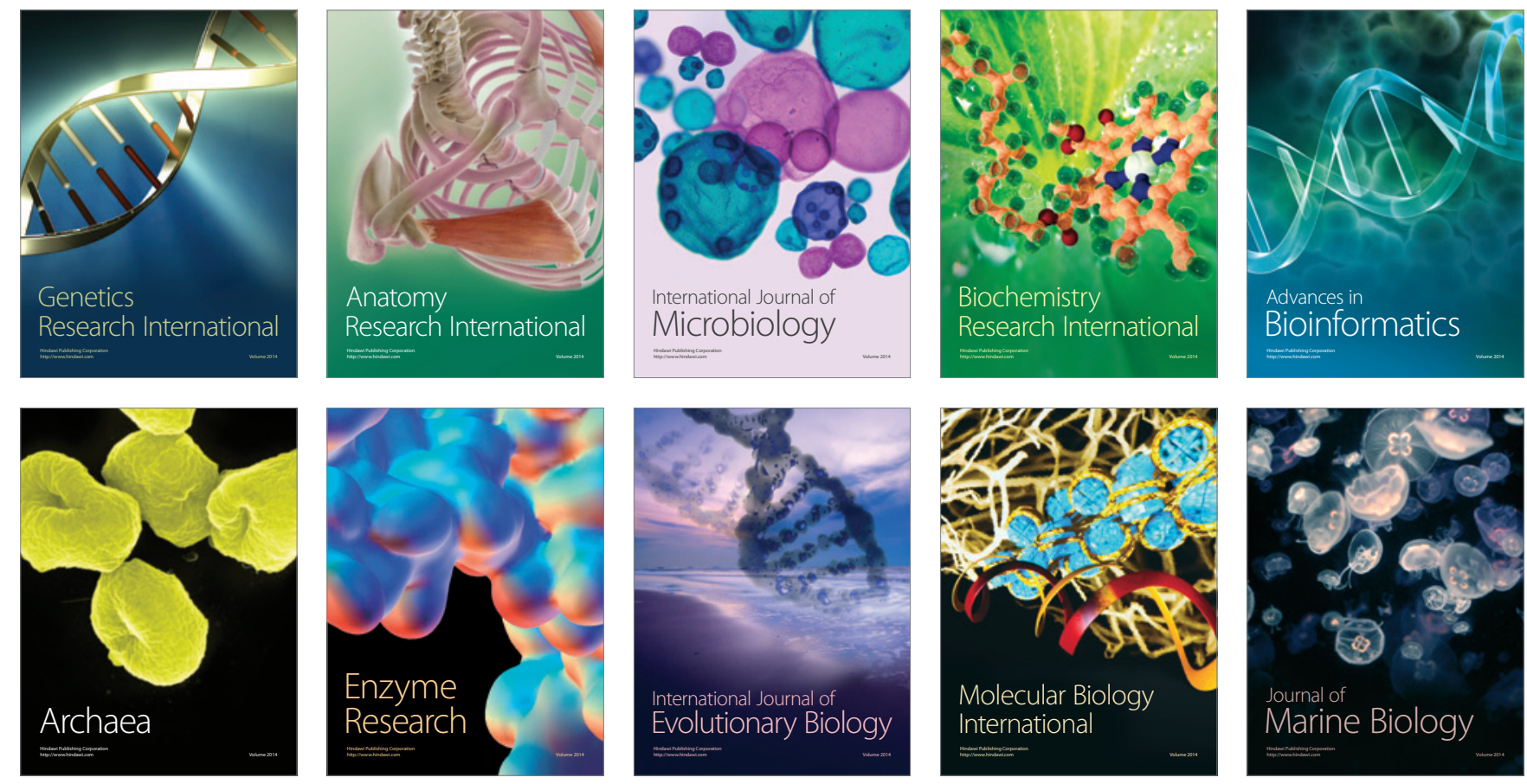